\title{
How to approach and treat VAP in ICU patients
}

\author{
Bárbara Borgatta ${ }^{1,2^{*}}$ and Jordi Rello $1,2,3,4$
}

\begin{abstract}
Background: Ventilator-associated pneumonia (VAP) is one of the most frequent clinical problems in ICU with an elevated morbidity and costs associated with it, in addition to prolonged MV, ICU-length of stay (LOS) and hospital-length of stay. Current challenges in VAP management include the absence of a diagnostic gold standard; the lack of evidence regarding contamination vs. airway colonization vs. infection; and the increasing antibiotic resistance. We performed a Pubmed search of articles addressing the management of ventilator-associated pneumonia (VAP). Immunocompromised patients, children and VAP due to multi-drug resistant pathogens were excluded from the analysis. When facing a patient with VAP, it's important to address a few key questions for the patient's optimal management: when should antibiotics be started?; what microorganisms should be covered?; is there risk for multirresistant microorganisms?; how to choose the initial agent?; how microbiological tests determine antibiotic changes?; and lastly, which dose and for how long?. It's important not to delay adequate treatment, since outcomes improve when empirical treatment is early and effective. We recommend short course of broad-spectrum antibiotics, followed by de-escalation when susceptibilities are available. Individualization of treatment is the key to optimal management.
\end{abstract}

Keywords: Ventilator-associated pneumonia, Nosocomial pneumonia, Treatment, Antibiotic, Management

\section{Background}

Ventilator-associated pneumonia (VAP) is one of the most frequent clinical problems in ICU. With an estimated incidence from 5-20 cases per 1.000 mechanical ventilation (MV) days; which has decreased over the last decade with the implementation of care bundles. However it still remains as the most frequent infection amongst critically ill patients and as the main cause of antibiotic prescription in ICU [1-4]. Despite presenting a low attributable mortality (less than 10\%); its burden relies on the elevated morbidity and costs associated with it, such as an estimated excess of cost as high as $\$ 40,000$ per patient's episode, in addition to prolonged MV, ICU-length of stay (LOS) and hospital-length of stay $[2,5,6]$.

VAP represents $80 \%$ of hospital-acquired pneumonia (HAP) and is defined as pneumonia developing after 48$72 \mathrm{~h}$ of MV. Many screening and diagnostic criteria have been used in order to an early identification of VAP and differentiation from ventilator-associated tracheobronquitis (VAT), with suboptimal results since radiological findings in the critically ill lack sufficient sensitivity and

\footnotetext{
* Correspondence: bborgattab@gmail.com

'Critical Care Department, Hospital Universitario Vall d'Hebron, Barcelona, Spain

2Vall d'Hebron Institute of Research, Barcelona, Spain

Full list of author information is available at the end of the article
}

specificity. Recently, Centers for Disease Control and Prevention (CDC) and Klompas et al. have established a new surveillance strategy for the screening of infectionrelated ventilator-associated complications (IVAC) [7] that represents a major change in VAP diagnosis paradigm, and focusing on sustained hypoxemia (lasting 2 calendar days) as a sine qua non characteristic of VAP, even in the absence of clear findings in the Rx. IVAC include all patients with 3 or more days of MV; with worsening of oxygenation lasting 2 calendar days, identified as increase in $\mathrm{FiO} 2$ or PEEP; which can be classified as possible VAP and probable VAP, depending on the criteria they meet.

Current challenges in VAP management include the absence of a diagnostic gold standard; the lack of evidence regarding contamination $v s$. airway colonization $v s$. infection; and the increasing antibiotic resistance.

\section{VAP management}

When facing a patient with VAP, it's important to address a few key questions for the patient's optimal management: when should antibiotics be started?; what microorganisms should be covered?; is there risk for multirresistant microorganisms?; how to choose the initial agent?; how microbiological tests determine antibiotic changes?; and lastly, which dose and for how long? See Figure 1. 


\section{VH-ICU Paradigm}

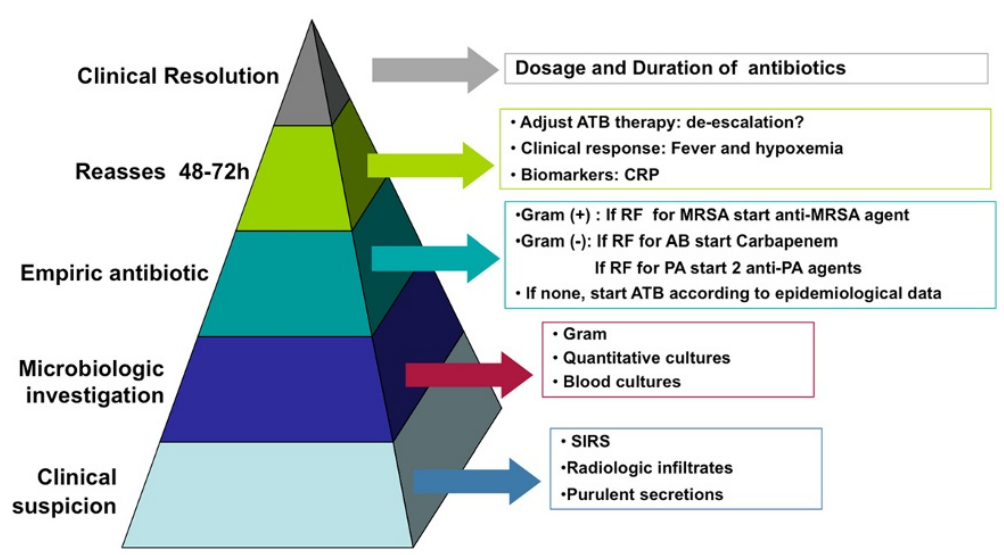

Figure 1 VH-ICU Paradigm for VAP. AB: Acinetobacter baumanii, ATB: antibiotic, CRP: C-reactive protein, MRSA: methicilin-resistant Staphilococcus aureus, PA: Pseudomonas aeruginosa, SIRS: systemic inflammatory response syndrome.

\section{Antibiotic start and choice}

It has been well documented that delayed effective therapy increases morbidity and mortality rate among patients with VAP $[3,8]$. Indeed, changing to an active agent after microbiology reports may not improve patient's outcomes [9]. Initial antibiotic should be active against likely pathogens; therefore its choice should be based on prior antibiotic exposure, patient co-morbidities, length of hospitalization and local epidemiology. Special considerations should be taken with patients with Health-care associated pneumonia (HCAP), since causative organism differs with higher probability for multi-drug resistant (MDR) pathogens. This subset of patients include recent hospitalization in acute care facility ( $<90$ days), resides in a nursing home or longterm care facility; received recent intravenous antibiotic therapy, chemotherapy, or wound care within the past 30 days of the current infection; or attended a hospital or hemodialysis clinic [10].

We support prompt antibiotic initiation with a short course of broad spectrum antibiotics, followed by deescalation when susceptibilities are available [11]; stressing that initial narrow-spectrum antibiotic should not be used. Certainly, besides microbiological sensitivities, lung penetration of active agents is a crucial matter that has to be considered.

Combined therapy is a long established practice in ICU, especially in VAP caused by $P$. aeruginosa because of its high rates of resistance and initial ineffective antibiotic therapy [12]. Many studies support that in bacteremic infections and VAP due to $P$. aeruginosa, combination therapy improves appropriate empirical therapy [10,13-15]; moreover a meta-analysis was able to detect reduced mortality in this subset of patients (OR 0.50, 95\% CI 0.300.79 ), and not in infection due to other gram-negative bacilli [13]. When analyzed by severity-of-illness, combined therapy in patients at high risk of death is significantly associated with reduced mortality only in the subset of patients with shock, whereas patients without shock have worse outcomes, probably due to toxicity $[16,17]$.

\section{Predicting causative organism}

Overall, VAP's main causative microorganisms are Pseudomonas aeruginosa and Staphylococcus aureus [3]. When considered by the time of onset, early-VAP (within the first 4 days of MV) is usually associated with normal oropharynx flora; such as S. pneumoniae, S. aureus and $H$. influenzae. However, a multicenter study showed a high prevalence $(50.7 \%)$ of potentially resistant microorganisms (PMR) in this subset of patients with no risk factors for PMR [18]. Late-VAP is largely caused by aerobic Gramnegative bacilli, of which up to $70 \%$ of cases are due to P. aeruginosa, Acinetobacter baumannii, or methicilinresistant S. aureus (MRSA). Also differences are seen in surgical and neurological patients, where $S$. aureus is the main pathogen [1-3].

Strategies based on guidelines are accurate for predicting causative microorganism and thus appropriate initial antibiotic in VAP $(97.9 \%, \mathrm{p}<0.05)$, but also are endotracheal aspirates from samples retrieved 2 days before the onset of VAP [19].

\section{Tailoring antibiotic treatment}

Standard antibiotic dosage has proven to be insufficient (under-dosage) in critically ill patients with severe sepsis, especially when they undergo continuous renal replacement or ECMO therapies [20,21]. A recent multicenter study addressing antibiotic levels in ICU patients treated with standard doses of betalactams, showed that $16 \%$ of them do not meet adequate levels and that it was associated with worse outcomes, while patients who achieved 
$50 \%$ and $100 \%$ ratios of free antibiotic concentrations above the minimum inhibitory concentration of the pathogen were associated with positive clinical outcome (OR: 1.02 and 1.56, respectively, $\mathrm{p}<0.03)$ [22]. Suggesting that antibiotic dosage and form of administrations should be personalized in order to improve patient's outcomes.

A new approach in VAP treatment is the use of nebulized antibiotics. Its main appeal is that allows achieving high local concentration of antibiotics, with fast clearance, which reduces risk for development of resistance, and with minimal absorption that translates into less toxicity. Even though many issues have to be improved, such as effective delivery systems and optimal formulations that are able to reach the alveoli and are well tolerated by the patients [23]; it poses as a desirable strategy for VAP antibiotic treatment, especially in multirresistant strains where active agents have elevated risk of toxicity. Disadvantages include frequent ventilator's filter obstruction, which some groups solve by routinely change after each administration [24].

Recent studies are lacking of robust data, in spite of which, nebulized therapy has shown to be effective. Nebulized monotherapy has proven to be non-inferior to IV therapy; and as adjunctive to IV regimens is associated with higher antibiotic concentrations at target tissue and less number of antibiotics per patient per day [24-28], and in some cases respiratory eradication of the microorganism [24,29]. Available formulations for nebulization include tobramycin, aztreonam, ceftazdime, amikacyn and colistin.

\section{Duration of treatment}

Optimal duration of antibiotic therapy is still controversial. Until recently, it was standard practice antibiotic regimens of minimum 15 days for uncomplicated infections [3]. Current trends favor short courses of antibiotics of 78 days if patient's response is satisfying; always individualizing to resolution. This approach is has equivalent clinical cure rates than long courses [30] and enables the reduction of side effects, costs and development of resistant phenotypes [3]. A recent meta-analysis concluded that short courses are associated with more antibiotic free days without any detrimental effect on mortality, besides the fact that prolonged antibiotic courses do not prevent recurrences $[30,31]$. Not to mention that in patients with VAP and negative bronchoalveolar lavage cultures, early antibiotic discontinuation does not affect mortality and is associated with fewer respiratory and multidrug resistant superinfections $(10.0 \%$ vs. $28.6 \%$ and $7.5 \%$ vs. $35.7 \%, \mathrm{p}<0.05$ respectively) [32].

\section{Optimization of antibiotics}

Optimization of antibiotics does not mean strictly following guidelines; instead it means empowerment, stewardship and team working. Antibiotic stewardship is a simple and cost-effective way to improve clinical outcomes while minimizing antibiotic side effects and its negative consequences; maintaining quality of care $[33,34]$.

\section{What's next?}

Research should be directed towards the development of ultra-fast diagnostic techniques that can immediately predict causative microorganism, without the need of specimen processing and also detect multirresistance mechanisms to avoid inadequate initial antibiotic treatment.

\section{Conclusions}

Getting it right the first time: It's important not to delay adequate treatment, since outcomes improve when empirical treatment is early and effective. Prompt appropriate therapy, then step-down: we recommend short course of broad-spectrum antibiotics, followed by de-escalation when susceptibilities are available. Individualize always!: regarding dosage, way of administration and duration based on clinical response.

\section{Abbreviations}

CDC: Centers for disease control and prevention; HAP: Hospital-acquired pneumonia; HCAP: Health-care associated pneumonia; LOS: Length of stay; MDR: Multi-drug resistant; MRSA: Methicilin-resistant S. aureus; MV: Mechanical ventilation; PMR: Potentially resistant microorganisms; VAP: Ventilator-associated pneumonia; VAT: Ventilator-associated tracheobronquitis.

\section{Competing interest}

Jordi Rello has served in the as board and speaker bureaus for Pfizer, Astellas, and Cubicin. Bárbara Borgatta has no competing interest.

\section{Authors' contribution}

$\mathrm{BB}$ and JR contributed equally to the writing of this manuscript. All authors read and approved the final manuscript.

\section{Acknowledgment}

Supported in part by: FIS PI11/01122.

\section{Author details}

${ }^{1}$ Critical Care Department, Hospital Universitario Vall d'Hebron, Barcelona, Spain. ${ }^{2}$ Vall d'Hebron Institute of Research, Barcelona, Spain. ${ }^{3}$ CIBERES, Barcelona, Spain. ${ }^{4}$ Universitat Autònoma de Barcelona, Barcelona, Spain.

Received: 5 February 2014 Accepted: 17 April 2014 Published: 30 April 2014

\section{References}

1. Chastre J, Fagon JY: Ventilator-associated pneumonia. Am J Respir Crit Care Med 2002, 165:867-903.

2. Rello J, Ollendorf DA, Oster G, Vera-Llonch M, Bellm L, Redman R, Kollef MH, VAP Outcomes Scientific Advisory Group: Epidemiology and outcomes of ventilator-associated pneumonia in a large US database. Chest 2002, 122:2115-2121.

3. Rello J, Diaz E: Pneumonia in the intensive care unit. Crit Care Med 2003, 31:2544-2551.

4. Vincent JL, Rello J, Marshall J, Silva E, Anzueto A, Martin CD, Moreno R, Lipman J, Gomersall C, Sakr Y, Reinhart K, EPIC II Group of Investigators: International study of the prevalence and outcomes of infection in intensive care units. JAMA 2009, 302:2323-2329. 
5. Safdar N, Dezfulian C, Collard HR, Saint S: Clinical and economic consequences of ventilator-associated pneumonia: a systematic review. Crit Care Med 2005, 33:2184-2193

6. Restrepo Ml, Anzueto A, Arroliga AC, Afessa B, Atkinson MJ, Ho NJ, Schinner R, Bracken RL, Kollef MH: Economic burden of ventilator-associated pneumonia based on total resource utilization. Infect Control Hosp Epidemiol 2010, 31:509-515.

7. Magill SS, Klompas M, Balk R, Burns SM, Deutschman CS, Diekema D, Fridkin S, Greene L, Guh A, Gutterman D, Hammer B, Henderson D, Hess D, Hill NS, Horan T, Kollef M, Levy M, Septimus E, VanAntwerpen C, Wright D, Lipsett P: Developing a new, national approach to surveillance for ventilator-associated events. Crit Care Med 2013, 41:2467-2475.

8. Piskin N, Aydemir H, Oztoprak N, Akduman D, Comert F, Kokturk F, Celebi G: Inadequate treatment of ventilator-associated and hospital-acquired pneumonia: risk factors and impact on outcomes. BMC Infect Dis 2012, 12:268.

9. Luna CM, Vujacich P, Niederman MS, Vay C, Gherardi C, Matera J, Jolly EC: Impact of BAL data on the therapy and outcome of ventilator-associated pneumonia. Chest 1997, 111:676-685.

10. American Thoracic Society; Infectious Diseases Society of America: Guidelines for the management of adults with hospital-acquired, ventilator-associated, and healthcare-associated pneumonia. Am J Respir Crit Care Med 2005, 171:388-416.

11. Ibrahim EH, Sherman G, Ward S, Fraser VJ, Kollef MH: The influence of inadequate antimicrobial treatment of bloodstream infections on patient outcomes in the ICU setting. Chest 2000, 118:146-155.

12. Salva S, Borgatta B, Rello J: Pneumonia in inmunocompetent patients: combination antibiotic therapy. Minerva Anestesiol 2014, 80:495-503.

13. Safdar N, Handelsman J, Maki DG: Does combination antimicrobial therapy reduce mortality in Gram-negative bacteraemia? A meta-analysis. Lancet Infect Dis 2004, 4:519-527.

14. Garnacho-Montero J, Sa-Borges M, Sole-Violan J, Barcenilla F, Escoresca-Ortega A, Ochoa M, Cayuela A, Rello J: Optimal management therapy for Pseudomonas aeruginosa ventilator-associated pneumonia: an observational, multicenter study comparing monotherapy with combination antibiotic therapy. Crit Care Med 2007, 35:1888-1895

15. Martínez JA, Cobos-Trigueros N, Soriano A, Almela M, Ortega M, Marco F, Pitart C, Sterzik H, Lopez J, Mensa J: Influence of empiric therapy with a beta-lactam alone or combined with an aminoglycoside on prognosis of bacteremia due to gram-negative microorganisms. Antimicrob Agents Chemother 2010, 54:3590-3596.

16. Kumar A, Safdar N, Kethireddy S, Chateau D: A survival benefit of combination antibiotic therapy for serious infections associated with sepsis and septic shock is contingent only on the risk of death: a meta-analytic/meta-regression study. Crit Care Med 2010, 38:1651-1664.

17. Kumar A, Zarychanski R, Light B, Parrillo J, Maki D, Simon D, Laporta D, Lapinsky S, Ellis P, Mirzanejad Y, Martinka G, Keenan S, Wood G, Arabi Y, Feinstein D, Kumar A, Dodek P, Kravetsky L, Doucette S, Cooperative Antimicrobial Therapy of Septic Shock (CATSS) Database Research Group: Early combination antibiotic therapy yields improved survival compared with monotherapy in septic shock: a propensity-matched analysis. Crit Care Med 2010, 38:1773-85.

18. Martin-Loeches I, Deja M, Koulenti D, Dimopoulos G, Marsh B, Torres A, Niederman MS, Rello J, EU-VAP Study Investigators: Potentially resistant microorganisms in intubated patients with hospital-acquired pneumonia: the interaction of ecology, shock and risk factors. Intensive Care Med 2013, 39:672-681.

19. Luna CM, Sarquis S, Niederman MS, Sosa FA, Otaola M, Bailleau N, Vay CA, Famiglietti A, Irrazabal C, Capdevila AA: Is a strategy based on routine endotracheal cultures the best way to prescribe antibiotics in ventilator-associated pneumonia? Chest 2013, 144:63-71.

20. Ulldemolins M, Roberts JA, Lipman J, Rello J: Antibiotic dosing in multiple organ dysfunction syndrome. Chest 2011, 139:1210-1220.

21. Textoris J, Wiramus S, Martin C, Leone M: Overview of antimicrobial therapy in intensive care units. Expert Rev Anti Infect Ther 2011, 9:97-109.

22. Roberts JA, Paul SK, Akova M, Bassetti M, De Waele JJ, Dimopoulos G, Kaukonen KM, Koulenti D, Martin C, Montravers P, Rello J, Rhodes A, Starr T, Wallis SC, Lipman J, DALI Study Authors: DALI: Defining Antibiotic Levels in Intensive care unit patients: Are current beta-lactam antibiotic doses sufficient for critically ill patients? Clin Infect Dis 2014, 58:1072-1083.
23. Kollef $\mathrm{MH}$, Hamilton $\mathrm{CW}$, Montgomery AB: Aerosolized antibiotics: do they add to the treatment of pneumonia? Curr Opin Infect Dis 2013 26:538-544

24. Lu Q, Luo R, Bodin L, Yang J, Zahr N, Aubry A, Golmard JL, Rouby J, Nebulized Antibiotics Study Group: Efficacy of high-dose nebulized colistin in ventilator-associated pneumonia caused by multidrug-resistant Pseudomonas aeruginosa and Acinetobacter baumannii. Anesthesiology 2012, 117:1335-1347.

25. Niederman MS, Chastre J, Corkery K, Fink JB, Luyt CE, García MS: BAY41-6551 achieves bactericidal tracheal aspirate amikacin concentrations in mechanically ventilated patients with Gram-negative pneumonia. Intensive Care Med 2012, 38:263-271.

26. Lu Q, Yang J, Liu Z, Gutierrez C, Aymard G, Rouby JJ, Nebulized Antibiotics Study Group: Nebulized ceftazidime and amikacin in ventilatorassociated pneumonia caused by Pseudomonas aeruginosa. Am J Respir Crit Care Med 2011, 184:106-115.

27. Montgomery AB, Vallance $\mathrm{S}$, Abuan $\mathrm{T}$, Tservistas M, Davies A: A Randomized Double-Blind Placebo-Controlled Dose-Escalation Phase 1 Study of Aerosolized Amikacin and Fosfomycin Delivered via the PARI Investigational eFlow ${ }^{\circledR}$ Inline Nebulizer System in Mechanically Ventilated Patients. J Aerosol Med Pulm Drug Deliv 2014. [Epub ahead of print].

28. Arnold HM, Sawyer AM, Kollef MH: Use of adjunctive aerosolized antimicrobial therapy in the treatment of Pseudomonas aeruginosa and Acinetobacter baumannii ventilator-associated pneumonia. Respir Care 2012, 57:1226-1233.

29. Tumbarello M, De Pascale G, Trecarichi EM, De Martino S, Bello G, Maviglia R, Spanu T, Antonelli M: Effect of aerosolized colistin as adjunctive treatment on the outcomes of microbiologically documented ventilator-associated pneumonia caused by colistin-only susceptible gram-negative bacteria. Chest 2013, 144:1768-1775.

30. Capellier G, Mockly H, Charpentier C, Annane D, Blasco G, Desmettre T, Roch A, Faisy C, Cousson J, Limat S, Mercier M, Papazian L: Early-onset ventilator-associated pneumonia in adults randomized clinical trial: comparison of 8 versus 15 days of antibiotic treatment. PLoS One 2012, 7:e41290.

31. Dimopoulos G, Poulakou G, Pneumatikos IA, Armaganidis A, Kollef MH, Matthaiou DK: Short- vs long-duration antibiotic regimens for ventilator-associated pneumonia: a systematic review and meta-analysis. Chest 2013, 144:1759-1767

32. Raman K, Nailor MD, Nicolau DP, Aslanzadeh J, Nadeau M, Kuti JL: Early antibiotic discontinuation in patients with clinically suspected ventilator-associated pneumonia and negative quantitative bronchoscopy cultures. Crit Care Med 2013, 41:1656-63.

33. Rello J, Lipman J: Antibiotic prescription for respiratory tract infections in ventilated patients: where are we heading? Intensive Care Med 2013, 39:1644-1646.

34. Rello J: Antibiotic stewardship in hospital-acquired pneumonia. Chest 2013, 143:1195-1196.

doi:10.1186/1471-2334-14-211

Cite this article as: Borgatta and Rello: How to approach and treat VAP in ICU patients. BMC Infectious Diseases 2014 14:211.

\section{Submit your next manuscript to BioMed Central and take full advantage of:}

- Convenient online submission

- Thorough peer review

- No space constraints or color figure charges

- Immediate publication on acceptance

- Inclusion in PubMed, CAS, Scopus and Google Scholar

- Research which is freely available for redistribution 